\title{
Sexuality and HIV education: Time for a paradigm shift
}

\author{
Nicole Haberland \\ Population Council \\ Deborah Rogow
}

Follow this and additional works at: https://knowledgecommons.popcouncil.org/departments_sbsr-pgy

Part of the Demography, Population, and Ecology Commons, Family, Life Course, and Society

Commons, Gender and Sexuality Commons, and the International Public Health Commons

How does access to this work benefit you? Let us know!

\section{Recommended Citation}

Haberland, Nicole and Deborah Rogow. 2007. "Sexuality and HIV education: Time for a paradigm shift," Promoting Healthy, Safe, and Productive Transitions to Adulthood Brief no. 22. New York: Population Council. 


\section{Sexuality and HIV education: Time for a paradigm shift}

\section{Prepared by Nicole Haberland and Deborah Rogow}

F or decades, curriculum-based sexuality education has been a cornerstone of school- and community-based efforts to improve young people's sexual and reproductive health, and more recently to prevent HIV infection. Unfortunately, public discourse about sex education has been mired in polarizing debates that distract attention from determining how sex and HIV education programs might best achieve the shared goals of many different constituencies.

A recent comprehensive review of the impact of schoolbased sexuality and HIV education programs in developed and developing countries found that two-thirds of the programs reduced the risk associated with one or more reported sexual behaviors (Kirby, Laris, and Rolleri 2005). This finding is encouraging and has led experts to recommend broad implementation of adult-led, school-based sex and HIV education that includes key characteristics common to effective programs (Ferguson, Dick, and Ross 2006). Yet, the ongoing HIV epidemic-increasingly affecting females and young people, especially in developing countries-and the human costs of unwanted pregnancy and sexually transmitted infections underscore the urgent need to optimize sex and HIV education programs. Population Council analyses point to several key areas in need of rethinking.

1) The content of curricula has focused on specific behaviors but has not kept pace with the growing body of research demonstrating the effects of underlying gender attitudes and behaviors on young people's sexual health and well-being. Most of us are familiar with sex education programs that teach about specific risks of sexual behavior, as well as technologies and individual steps to mitigate those risks-whether they are

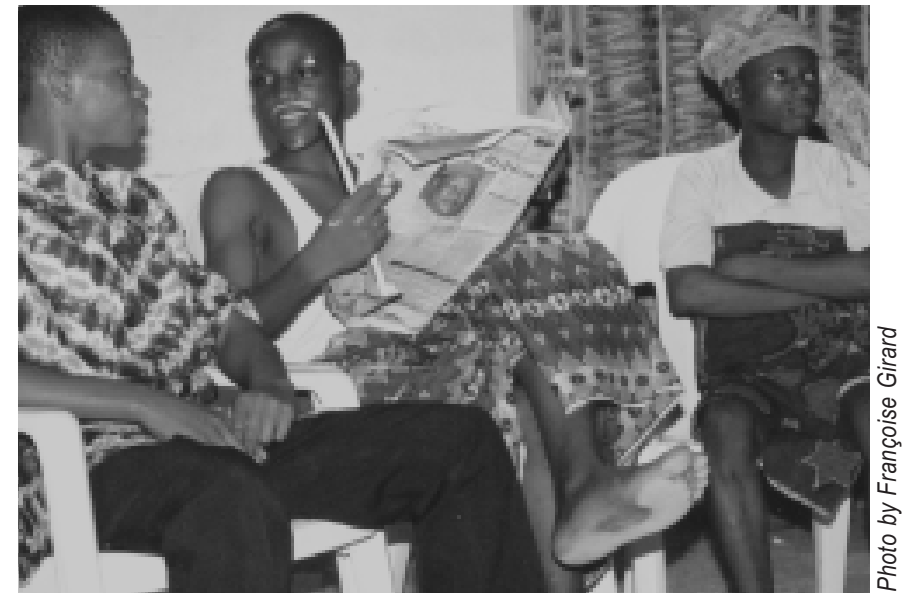

Nigerian adolescent boys participate in an education program that emphasizes critical thinking and learner-centered, interactive teaching techniques.

related to pregnancy prevention or AIDS prevention. However, from studies in both developed and developing countries, we know that harmful behaviors are associated with far more than the absence of such information: they are linked to attitudes about gender roles and unequal power in intimate relationships. For example, when people hold conservative attitudes about gender roles, studies have found a higher number of sexual partners (Karim et al. 2003), lower rates of condom use (Karim et al. 2003), and more reported symptoms of sexually transmitted infections (STIs) (Pulerwitz et al. 2006). Young women who have previously experienced sexual coercion are significantly less likely to use condoms (Koenig et al. 2004), are more likely to report unintended pregnancy (Koenig et al. 2004), and/or symptoms of genital tract infection (Erulkar 2004; Koenig et al. 2004) and are likelier to have more sexual partners (Erulkar 2004). 
Furthermore, males and females report different reasons for having sex. A study of college students in the United States found that men, significantly more than women, cited reasons related to the physical appearance and desirability of their partner, physical pleasure, experience seeking, and enhancement of social status. Women, significantly more than men, named expressing love for the person and realizing they were "in love" (Meston and Buss 2007). Similarly, a study in Nicaragua found that girls more often cited desire for love and approval, whereas boys mentioned curiosity and pleasure (Rani, Figuero, and Ainsle 2003). Few sex education programs address these gender issues in a meaningful way. Emerging findings show the positive effect of gender-awareness education for young men on their greater condom use and lower reported STI symptoms (Pulerwitz et al. 2006).

In addition to the likely benefit for sex-related behavior, improvements in gender attitudes may have positive effects on other areas of health, well-being, and civil society. For example, children's health and school attendance are influenced by gender norms that provide a greater voice for women. Gender equality may well be an important factor in men's and women's full participation in civic life. For example, multi-country data show that positive attitudes toward gender equality are a central element of the cultural change associated with democratic governance around the world (Inglehart, Norris, and Welzel 2002).

\section{Next steps}

The Population Council's Rethinking Sexuality Education initiative has been working toward a "social studies" approach that fosters the development of critical thinking skills and emphasizes learning and reflection about the ways that gender, rights, and other aspects of social context (such as race/ethnicity and class) affect sexual experience (Rogow and Haberland 2005). Young people can learn about, and reflect upon, how gender norms function. For example, how do messages about masculinity lead boys and men to "prove" their manhood and heterosexuality, including through sexual conquest and gender-based violence? And how do girls' economic circumstances interact with their status as females to increase their risk of HIV through unprotected, coerced, and/or transactional sex? It is time to take these leads and test them in systematic ways in a variety of settings.

\section{2) Although HIV and adolescent health experts repeatedly call for reaching young people at earlier ages, policymakers and program leaders have few viable options.}

For various reasons, policymakers and sex/HIV educators may be hesitant to transmit explicit messages about sex to pubescent and pre-pubescent young people. At the same time, these younger adolescents, whose attitudes toward gender are crystallizing, have little opportunity to question norms and practices that fundamentally shape their sexual lives-including child marriage, transactional sex, learned submissiveness/dominance, basic human rights, and citizen participation. Almost absent from schools are HIV/adolescent health programs that teach younger adolescents about fundamental issues of social studies; notions of equality/ inequality; self/others (community, family, and intimate relationships); and communication and decisionmaking tools that would set the stage for young people to make use of explicit information about sex, contraception, infection prevention, and the like at the appropriate time.

Next steps

Fostering programs that deal with the underpinnings of sexual behavior could allow institutions to reach youth at earlier ages. Would offering sexuality and HIV education at younger ages lead to better results over the long run? Communities and schools need clear guidance about the short- and long-term value of programs that examine broader issues of social context and do so at younger ages.

\section{3) What contributes to-or detracts from-classroom approaches to sex education?}

There are two issues to consider about the quality of the teaching of sex education, regardless of whether a program has made the decision to include issues of gender equality. The first issue is simply that gender bias is a reality in most classrooms, including those where sex and HIV education curricula are implemented. Too often, curricula, teachers, and pedagogic approaches may unwittingly privilege boys over girls, dampen girls' participation and motivation, condone the sexual harassment of girls, and reinforce existing gender stereotypes. Indeed, gender bias in schools has also been linked to girls' greater risk of premarital sex (Mensch et al. 2001). And so, in addition to enhancing the gender-equality content of curricula, there is a need to address the gendered nature of the classroom itself.

Second, most sexuality and HIV education curricula in developed countries include at least some participatory learning methods, interactive discussions, or other non-didactic approaches designed to enhance participants' learning and skill building. However, rote learning prevails in the vast majority of developing-country classrooms. Training teachers to use more interactive methods and discussion is a critical step for effective implementation of sexuality and HIV curricula. The use of "teaching methods that actively involve the participants and help them to personalize the information" has been identified as one of a number of key characteristics of the most effective programs (Kirby, Laris, and Rolleri 2005). There may be additional benefits. Participatory learning and an open culture in the classroom have been linked with positive attitudes toward gender equality (Pettersson 2003). Investments in training teachers in interactive, learner-centered methods and in fostering critical thinking skills could provide significant benefits both to educational and to sexual and reproductive health outcomes. 


\section{Next steps}

It is unlikely that the sex education community alone can support a general transformation of pedagogical approaches, but sexuality/ HIV education can function as a "leading edge" for developing such skills, and can influence other constituencies in the education field to advance such skills more generally. Gender biases in the classroom may be more amenable to change if specific interventions document the extent to which reinforcement of gender roles and norms is occurring in the classroom and provide specific tools to rectify these biases.

\section{4) What do evaluations of sex and HIV education programs} suggest about gender and about evaluation outcomes? The evaluation of sex and HIV education programs has focused on narrow outcome measures, and too little attention has been given to the significant gender differences in the results. Indeed, most evaluations of standard coeducational sex and HIV curricula show different effects on girls than on boys. In a review of 59 evaluations of co-ed sexuality and HIV education programs in the United States and developing countries that had a statistically significant effect on outcomes, the great majority had disparate effects for girls and boys (Haberland 2006). The implication-that girls and boys may have different learning needs with regard to their sexual lives-is consistent with the findings that girls and boys tend to give different reasons for having sex and that gender norms and images exert different pressures on girls and boys.

Moreover, the qualitative nature of young people's sexual experiences-including how willingly they engage in sex and whether they experience pleasure-has rarely been considered in evaluations of sex education. These contextual factors may be linked with sexual health indicators. For example, there is some suggestion that young women who believe they are entitled to pleasure from their partner have greater sexual self-efficacy, such as feeling confident in knowing how to use condoms or in discussing condom use (Horne and Zimmer-Gembeck 2006). Sexual self-efficacy has also been linked with protective behaviors such as condom use (Impett et al. 2006). It is regrettable that education about such an emotion-laden topic as sex tends to focus on a narrow set of behaviors (e.g., when will sex occur?, is a condom used?), while paying little attention to such outcomes as the sense of safety or of comfort with those experiences.

\section{Next steps}

Future studies might examine how the motivations for sex (pleasure, control of a partner, seeking love) influence girls' or women's vulnerability to coercion, their sexual self-efficacy, and their reproductive health. Research should also help determine the value of expanding evaluation to consider qualitative aspects of personal relationships and changes in gender attitudes. Research could help inform us about the value of coeducational and same-sex (or

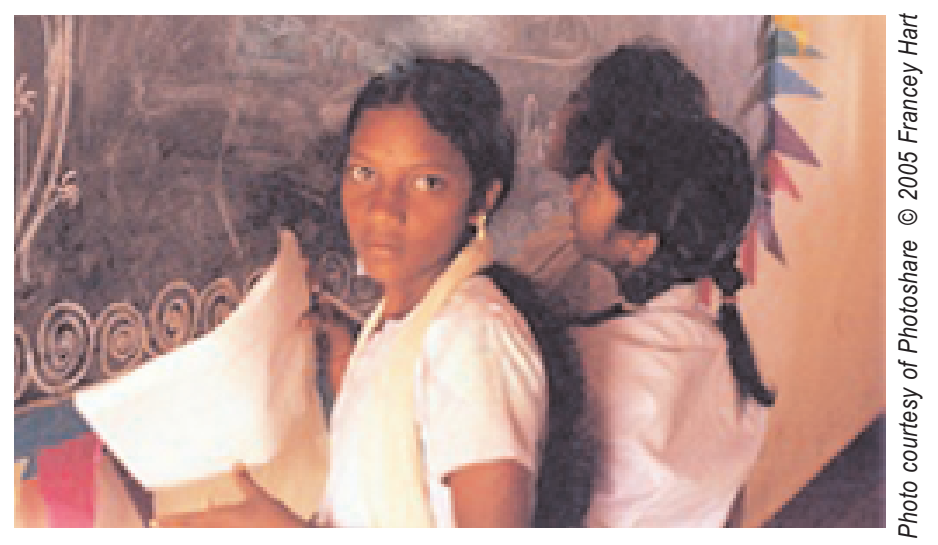

In India, girls learn about HIV/AIDS, including the underlying social factors.

partly same-sex) programs in different settings and with different content mix. Rigorous evaluations of new approaches, with longitudinal, longer-term follow-up and a broader range of outcome measures, are vital to understanding how we can provide more effective sex and HIV education.

\section{5) Are we reaching the young people we intend to reach?} Typically, programs with a wide reach are located in schools. In many developing countries, however, the proportion of 15-19-yearold girls in school is quite low. Consequently, a substantial proportion of young people, especially girls, are beyond the reach of school-based sex education programs.

In many settings-especially sub-Saharan Africa-a large proportion of girls either are not in school or, if in school, have not reached the middle or secondary school levels where sex and HIV education are typically offered. For example, in Senegal only 9 percent of 15-19-year-old girls are in secondary school; in Bangladesh only 20 percent; and in Kenya 13 percent (Population Council 2001). A Population Council study in three districts of Kenya found that between 79 percent and 94 percent of 12-18-year-old girls were in primary (not secondary) school (Mensch and Lloyd 1998). Children who enter school late may still be in primary school at the age when it would be appropriate for them to receive sex education.

\section{Next steps}

There is a need for a simple demographic assessment of the likely coverage of existing school-based programs on the basis of a country's patterns of school enrollment by age, gender, and race/ethnicity. The lessons learned about ways of improving the content and delivery of sex education should be applied to the support of nonschool-based programs that might reach broader audiences.

\section{Conclusion}

While we have learned a good deal about effective sexuality and HIV education, we can do much better. Several areas of research suggest that it is time to develop and test a "social studies" approach to sex and HIV education-one that starts earlier and 
fosters critical thinking skills, gender equality, and human rights. Such an effort may have important lessons for improved sexual and reproductive health outcomes and contribute to other aspects of young people's preparation for active, informed participation in civil society. The Population Council's Rethinking Sexuality Education initiative is working to put these ideas into practice and to evaluating them rigorously.

\section{References and related publications}

Dunkle, Kristin, Rachel Jewkes, Heather Brown, Glenda Gray, James McIntryre, and Sioban Harlow. 2004. "Gender-based violence, relationship power, and risk of HIV infection in women attending antenatal clinics in South Africa," Lancet 363: 1415-1421.

Erulkar, Annabel. 2004. "The experience of sexual coercion among young people in Kenya," International Family Planning Perspectives 30(4): 182-189.

Ferguson, Jane, Bruce Dick, and David Ross. 2006. "Conclusions and recommendations," in Preventing HIV/AIDS in Young People: A Systematic Review of the Evidence from Developing Countries, David Ross, Bruce Dick, and Jane Ferguson, editors. WHO Technical Report Series No. 938. Geneva: World Health Organization.

Foshee, Vangie and Karl Bauman. 1992. "Gender stereotyping and adolescent sexual behavior: A test of temporal order," Journal of Applied Social Psychology 22(20): 1561-1579.

Haberland, Nicole. 2006. "Gender and sexuality/HIV education," presentation at New Evidence on Curriculum-Based Reproductive Health and HIV Education for Youth: Global Research and Local Action, Washington, DC, 9-10 January.

Horne, Sharon and Melanie Zimmer-Gembeck. 2006. "The female sexual subjectivity inventory: Development and validation of a multidimensional inventory for late adolescents and emerging adults," Psychology of Women Quarterly 30: 125-128.

Impett, Emily, Deborah Schooler, and Deborah Tolman. 2006. "To be seen and not heard: femininity ideology and adolescent girls' sexual health," Archives of Sexual Behavior 35(2): 131-144.

Inglehart, Ronald, Pippa Norris, and Christian Welzel. 2002. "Gender equality and democracy," Online: World Values Survey. www.worldvaluessurvey.org/library/latestpub.asp, accessed 2 July 2007.

Karim, Ali Mehryar, Robert Magnani, Gwendolyn Morgan, and Katherine Bond. 2003. "Reproductive health risk and protective factors among unmarried youth in Ghana," International Family Planning Perspectives 29(1): 14-24.
Kirby, Douglas, B.A. Laris, and Lori Rolleri. 2005. "Impact of sex and HIV education programs on sexual behaviors of youth in developing and developed countries," Youth Research Working Paper No. 2. Research Triangle Park, NC: Family Health International.

Koenig, Michael, Iryna Zablotska, Tom Lutalo, Fred Nalugoda, Jennifer Wagman, and Ron Gray. 2004. "Coerced first intercourse and reproductive health among adolescent women in Rakai, Uganda," International Family Planning Perspectives 30(4): 156-163.

Mensch, Barbara, Wesley Clark, Cynthia Lloyd, and Annabel Erulkar. 2001. "Premarital sex, schoolgirl pregnancy, and school quality in rural Kenya," Studies in Family Planning 32(4): 285-301.

Mensch, Barbara and Cynthia Lloyd. 1998. "Gender differences in the schooling experiences of adolescents in low-income countries: The case of Kenya," Studies in Family Planning 29: 167-184.

Meston, Cindy and David Buss. 2007. "Why humans have sex," Archives of Sexual Behavior 36: 477-507.

Pettersson, Thorlief. 2003. "Basic values and civic education: A comparative analysis of adolescent orientations towards gender equality and good citizenship," Online: World Values Survey. www.worldvaluessurvey.org/library/latestpub.asp, accessed 2 July 2007.

Population Council. 2001. Facts about Adolescents from the Demographic and Health Survey: Statistical Tables for Program Planning. New York: Population Council.

Pulerwitz, Julie, Gary Barker, Marcio Segundo, and Marcos Nascimento. 2006. "Promoting more gender-equitable norms and behaviors among young men as an HIVIAIDS prevention strategy," Horizons Final Report. Washington, DC: Population Council.

Rani, Manju, Maria Elena Figueroa, and Robert Ainsle. 2003. "The psychosocial context of young adult sexual behavior in Nicaragua: Looking through the gender lens," International Family Planning Perspectives 29(4): 174-181.

Rogow, Deborah and Nicole Haberland. 2005. "Sexuality and relationships education: Toward a social studies approach," Sex Education 5(4): 333-344. Also available in Spanish and French.

Timreck, E., D. Rogow, and N. Haberland (eds.). 2007. "Addressing gender and rights in your sex/ HIV education curriculum: A starter checklist," New York: Population Council.

\section{Donors}

UK Department for International Development (DFID), The Ford Foundation, United Nations Population Fund (UNFPA)

\section{For more information or for copies of other briefs, contact publications@popcouncil.org}

For additional resources see www.popcouncil.org/pgy

Population Council, One Dag Hammarskjold Plaza, New York, New York 10017 USA

(C) 2007 by The Population Council, Inc. 